\section{The knowledge about the adolescent girls' genitals and hygiene who live in Sanliurfa, applications and factors that affect}

\section{Şanliurfa'da adölesan dönemde kızların genital bölge ve hijyeni ile ilgili bilgi, uygulamaları ve etkileyen faktörler}

\author{
Yasemin Yilmaz ${ }^{1}$ \\ Selma Kahraman ${ }^{2}$
}

\begin{abstract}
This descriptive study aimed to determine the knowledge and practices regarding genital hygiene among adolescent girls in Şanliurfa. The population of study was 42358 high school girl students. The sample calculated according the formula from the population was 600 girls. The high school girl students of each central districts of Şanliurfa were determined according to the layered sampling method. The data were collected with questionnaire form and analysed with SPSS 11.5 package program using descriptive statistics an Chi-Square test. The ratio of girls who answered the definition of genital hygiene as partly true was $57.2 \%$. $35 \%$ of the girls expressed that they did not take any information about genital area and hygiene before. $54.9 \%$ of participants answered cleaning styles of genital area as "front to back". $74.8 \%$ had itching problem in genital area. $75.2 \%$ of the students answered vaginal discharge as a normal condition. $37.3 \%$ had transparent and odorless discharge. The girls who employed healthy cleaning practices (use of both water and toilet paper) attended 1st grade $(19.1 \%)$ and 3rdgrade (35.3\%) in High Schools $(\mathrm{X} 2=17,121 \mathrm{p}<0,01)$. In the study, the
\end{abstract}

\section{Özet}

$\mathrm{Bu}$ araştırmanın amacı, Şanlıurfa'da adölesan dönemde kızların genital hijyen bilgi ve uygulamalarını belirlemektir. Araştırmanın evreni, 42358 liseye giden kız öğrencidir. Evreni bilinen örneklem formülüne göre araştırmanın örneklem büyüklüğü 600 kişidir. İlin merkez ilçeleri tabaka olacak şekilde tabakalı örneklem yöntemine göre her ilçede yer alan liseye giden kız öğrenci sayısı belirlenmiştir. Araştırmanın verileri, anket formu ile toplanmıştır. Veriler, SPSS 11.5 paket programı ile tanımlayıc1 istatistik ve ki kare test analizi ile değerlendirilmiştir. Genital hijyenin tanımını kısmen doğru tanımlayan kız oranı \%57,2'dir. Daha önce "genital bölge ve hijyeni" konusu ile ilgili bilgi almadığını ifade edenlerin oranı \%35,0'dır. Katulımciların \%54,9’u, genital bölgelerini “önden arkaya” doğru temizlediğini ifade etmiştir. Genital bölgesinde kaşıntısı olan kızların oranı \%74,8'dir. Öğrencilerin \%75,2'si vajinal akıntınin normal bir durum olduğunu, \%37,3'ü şeffaf ve kokusuz vajinal akıntıya sahip olduğunu belirtmiştir. Genital bölgeyi sağlıklı yöntem (su ve tuvalet kâğıdının birlikte kullanımı) ile temizleyen kızların \%19,1'inin lise 1., \%35,3'ünün lise 3.sinifta okumaktadır

\footnotetext{
1 Öğr. Gör. Harran Üniversitesi, Sağlık Bilimleri Fakültesi, Hemşirelik Bölümü, yaseminyilmaz@harran.edu.tr

2 Doç. Dr., Harran Üniversitesi, Sağlık Bilimleri Fakültesi, Hemşirelik Bölümü, skahraman1308@gmail.com
} 
Yılmaz, Y., \& Kahraman, S. (2019). Şanlıurfa'da adölesan dönemde kızların genital bölge ve hijyeni ile ilgili bilgi, uygulamalar1 ve etkileyen faktörler. Journal of Human Sciences, 16(3), 823-832. doi:10.14687/jhs.v16i3.5678

knowledge level and good practices regarding genital area health increased with increased socio-economic level, adolescent age and mother knowledge level and grade. The knowledge level and practices of genital health area were found as inadequate and lacking.

Keywords: Adolescent; Hygiene; Knowledge; Method; Nursing.

(Extended English summary is at the end of this document) $(\mathrm{p}<0,01)$. Adölesanların yaşı, gelir durumu, anne eğitim durumu ve sinıf düzeyi arttıkça genital bölge sağllğına ilişkin doğru bilgi ve uygulamaların arttı̆̆1 saptanmıştır. Bu çalışmada genital bölge sağllğı ile ilgili bilgi ve uygulamalarının yetersiz ve eksik olduğu belirlenmiştir.

Anahtar Kelimeler Adölesan; Hijyen; Bilgi; Uygulama; Hemşirelik.

\section{Giriş}

Adölesan, insan evriminde kritik bir dönem olarak bir insanın üreme kapasitesine ulaşma durumudur (Türkiye İstatistik Kurumu, 2017; Özcebe \& Dam, 2007). Dünya Sağlık Örgütü (DSÖ)'ne göre; adölesan (ergenlik) dönemi 10-19 yaş arasını kapsamaktadır. Ülkemizin 2017 yılında yaptığ1 nüfus sayımına göre nüfusun \%16,1'ini adölesanlar oluşturmaktadır (Türkiye İstatistik Kurumu, 2017).

Adölesan dönemi, psikolojik açıdan adaptasyon ve seksüel organların tam matürasyon gösterdiği önemli bir süreçtir (Özcebe, \& Dam, 2007; Chandra-Mouli., et al. 2015). DSÖ'nün 21. yüzyılda ulaşmayı amaçladığı 21 sağlık hedefi listesinin başında yaşama sağlıklı başlangıç ve gençlerin sağlığını geliştirmesi yer almaktadır. Gençlerin ihmal edilmesi hem kısa vadede hem de gelecek yıllarda sorunlara yol açabilir. Yeniliğe, değişime, gelişmeye en açı olan bu yaş grubuna doğru yöntemlerle, doğru yerde, doğru kişilerle ulaşıldığında ülkemizin üreme sağllğ1 statüsünün gelişmesine büyük katkı sağlanacaktır. DSÖ bu dönemi, üreme sağlığının öncelikli alanlardan biri olarak belirlemiş ve ergenlik döneminden başlamak üzere üreme sağllğı açısından hizmet gereksinimin kadınlarda daha fazla olduğunu saptamışır (Fakhri, Hamzehgardeshi, Golchin, \& Komili, 2012; Dalbudak, \& Bilgili, 2013; Aslan, Bektaş, Başgol, Demir, \& Vural, 2014; Topuz, Büyükkayac1, \& Güneş, 2015; Demirbağ, Çan, Köksal, \& Kaya, 2013; Dağ, Dönmez, Şirin, \& Kavlak, 2012).

Adölesan kızlar üreme sağlığı sorunlarını sık yaşamaları, üreme sağllğı hizmetlerinden en az yararlanan grup olmaları, nüfus içerisinde oranlarının fazla olması gibi nedenlerle üzerinde durulması gereken özellikli bir gruptur (Chandra-Mouli, et al., 2015; Dalbudak, \& Bilgili, 2013; Das, et al., 2015). Bu uzun dönem içinde kızlar, dış genitallerin mukozal yapısı, organların yakın komşulukları gibi anatomik nedenler ve menstürasyon dönemi ve boşaltım sonrası uygun olmayan genital bölge temizliği, yetersiz el yıkama, uygun iç çamaşırı kullanmama gibi yanlış hijyenik alıskanlıklar nedeni ile erkeklere göre daha fazla risk altındadırlar. Üreme sağlığı sorunları ile ilgili olarak kadın ve erkek arasındaki eşitsizlikler doğumdan ölüme kadar kadınların aleyhine olarak devam ettiği bilindiğinden: Türkiye'de Sağlık Bakanlığı tarafindan kadın sağlığı ile ilgili program ve projeler yürütülmektedir. Bu projelerin genel amacı ise bireylerin adölesan sağllğı konusunda bilinçlenmesi ve sağlıklı bir adölesan dönemi geçirmelerini sağlamak, adölesan sağlığını geliştirmek ve korumaktır (Dalbudak, \& Bilgili, 2013; Aslan, et al., 2014; Topuz, Büyükkayac1, \& Güneş, 2015; Demirbağ, et al., 2013).

Türkiye'de doğurganlık çağındaki kadınlarda jinekolojik sağlık sorunları ve bu sorunların sıklığ1 konusunda geneli temsil edecek veriler oldukça sinırlıdır. Bu konuda yapılan bölgesel çalışmalarda genital enfeksiyonların yaygın olarak (sıklık \%52-92 arasında) görüldüğü 
Yılmaz, Y., \& Kahraman, S. (2019). Şanlıurfa'da adölesan dönemde kızların genital bölge ve hijyeni ile ilgili bilgi, uygulamalar1 ve etkileyen faktörler. Journal of Human Sciences, 16(3), 823-832. doi:10.14687/jhs.v16i3.5678

bildirilmektedir (Topuz, Büyükkayac1, \& Güneş, 2015; Demirbağ, et al., 2013; Dağ, et al., 2012; Das, et al.,2015; Ünsal, 2013). Adölesan dönem genital yol enfeksiyonlardan korunma yolları, belirtileri, tanı ve tedavi yöntemleri ile ilgili bilginin verileceği, yeni davranış biçimlerinin kazandırılabileceği en uygun dönemdir (Das, et al.,2015; Ünsal, 2013). Adölesan kızların doğru hijyen uygulamaları hakkında bilinçlendirilmesi özellikle toplumla birebir çalışan hemşirelerin önemli sorumluluklarından biridir. Hemşireler ilk olarak okul sağlığı kapsamında eğitimlerle başlayabilir.

\section{Araştırmanın Amacı}

Bu araştırmanın amacı, Şanlıurfa'da adölesan dönemde olan kız öğrencilerin genital hijyen bilgi ve uygulamalarını incelemektir.

\section{Yöntem}

3.1. Evren ve Örneklem; Bu araştırmanın evreni Şanlıurfa Merkez'de liseye giden tüm genç kızlardır. İl Milli Eğitim Müdürlüğünden 2014 yılı verilerine göre, Şanlıurfa'nın merkezinde liseye giden kız öğrenci sayıs1 42358'dir. Araştırmanın minimum örneklem büyüklüğü $\alpha=0,05$ anlamlılık düzeyi, $\mathrm{d}=0.05$ örnekleme hatası, $\mathrm{p}=0,5$ ve $\mathrm{q}=0,5$ alınarak 381 olarak hesaplanmıştır (10). Çalışmanın minimun örneklem büyüklüğü evrenin temsil etme gücünü artırmak amacıyla örneklem 600'e artırılmıştır. Şanlıurfa merkezi 3 ilçeden oluşmaktadır. Bu çerçevede tabakalı örnekleme yöntemi kullanılarak 3 merkez ilçe tabaka olarak gösterilerek tabaka ağırlı̆̆1 tespit edilmiştir. Her bir ilçeden basit rastgele örneklem yöntemine göre bir lise seçilmiştir. Şanlıurfa Merkez Eyyübiye İlçesi sosyoekonomik olarak düşük, Haliliye ilçesi orta, Karaköprü İlçesi yüksek sosyoekonomik seviyeye sahiptir.

3.2. Veri Toplama Aracı: Araştırmanın verileri, iki bölümden oluşan bir anket formu ile toplanmıştır. Veri toplama formun birinci bölümü, öğrencilerin ve ailesinin sosyo-demografik özelliklerini inceleyen 9 sorudan oluşmaktadır. İkinci bölüm öğrencilerin genital bölge ve hijyeni ile ilgili bilgi düzeylerini inceleyen 36 soru içermektedir.

3.3. Araştırmanın Etik Yönü: Araştırmanın uygulanabilmesi için İl Milli Ĕ̆gitim Müdürlüğü ve Şanlıurfa Valiliği’nden yazılı izin, araştırmanın etik uygunluğu açısından Harran Üniversitesi Etik kurul Komisyonundan (216-08.10.2013) etik kurul onayı ve araştırmaya katılan kız öğrencilerden yazılı bilgilendirilmiş onam alınmıştır.

3.3. Verilerin Değerlendirmesi: Çalışma verilerini değerlendirmek için tanımlayıcı istatistikler (frekans, yüzde) kullanılmış ve kız öğrenci ve ailesinin sosyo-demografik özellikleri ile kız öğrencilerin genital hijyen hakkında bilgi ve uygulamaları arasında ilişki testi olarak ki kare analizi yapılmıştır. 
Yılmaz, Y., \& Kahraman, S. (2019). Şanlıurfa'da adölesan dönemde kızların genital bölge ve hijyeni ile ilgili bilgi, uygulamalar1 ve etkileyen faktörler. Journal of Human Sciences, 16(3), 823-832. doi:10.14687/ihs.v16i3.5678

\section{Bulgular}

Tablo 1. Kız Öğrencilerin Sosyo-demografik Özellikleri

\begin{tabular}{|l|l|l|}
\hline Değişkenler & Say1 & Yüzde \\
\hline Yaş & & \\
$14-15$ & 216 & 36,0 \\
$16-17$ & 330 & 55,0 \\
$18-19$ & 54 & 9,0 \\
\hline Sinıf & & \\
Lise 1 & 153 & 25,5 \\
Lise & 148 & 24,7 \\
Lise 3 & 187 & 31,2 \\
Lise 4 & 112 & 18,7 \\
\hline Annenin Ë̆itim Durumu & & \\
Okur Yazar Olmayan & 208 & 34,7 \\
Okur Yazar Olan & 82 & 13,7 \\
İlkokulu Mezunu & 222 & 37,0 \\
Ortaokul Ve Üzeri & 88 & 14,6 \\
\hline Babanın Eğitim Durumu & & \\
Okur Yazar Olmayan & 42 & 7,0 \\
Okur Yazar Olan & 37 & 6,2 \\
İlkokulu Mezunu & 227 & 37,8 \\
Ortaokul Ve Üzeri & 294 & 49,0 \\
\hline Aile Tipi & & \\
Çekirdek Aile & 441 & 73,5 \\
Geniş Aile & 159 & 26,5 \\
\hline Ailenin Gelir Düzeyi & & \\
Düşük Gelir Düzeyi (Asgari Ücret Ve Altı) & 179 & 29,8 \\
Orta Gelir Düzeyi (Asgari Ücret-1500 Tl) & 252 & 42,0 \\
Yüksek Gelir Düzeyi (1500 TL Ve Üzeri) & 169 & 28,2 \\
\hline
\end{tabular}

$\mathrm{n}=600$

Tablo 1'de görüldüğü gibi; araştırmaya katılan kız öğrencilerin \%55,0’1nın 16-17 yaş grubunda olduğu saptanmıştır. Öğrencilerin annelerinin \%14,6's1, babaları \%49,0'ının ortaokul ve üzeri eğitim aldığı bulunmuştur. Araştırmaya katılan kız öğrencilerin \%73,5’i çekirdek aile yapısına ve ailelerin $\% 42,0 ’ 1$ orta gelir düzeyine sahiptir.

Tablo 2- Kız Öğrencilerin Genital Bölge ve Hijyeni ile İlgili Bilgi Durumları

\begin{tabular}{|l|l|l|}
\hline Özellikler & Sayı & Yüzde \\
\hline Genital hijyen tanımı & & \\
Bilmiyor & 257 & 42,8 \\
Kısmen Doğru & 343 & 57,2 \\
\hline Daha önce 'genital bölge ve hijyeni” konusu ile ilgili bilgi alma & & \\
durumu & & \\
Almayan & 210 & 35,0 \\
Alan & 390 & 65,0 \\
\hline Genital bölge temizliğinde malzeme tercihi & \\
Yanlış malzeme (Parfüm, Alkol...vb) & 340 & 56,7 \\
Sadece su ya da tuvalet kâğıdı & 15,2 \\
Doğru malzeme (su ve tuvalet kâğıdının birlikte kullanımı) & 169 & 28,2 \\
\hline Genital bölge temizleme yöntemi & \\
Yanlış Tercih (arkadan öne, gelişi güzel) & 271 & 45,1 \\
Doğru Tercih (önden arkaya) & 329 & 54,9 \\
\hline Genital Bölgede Kaşıntı Olma Durumu & & 74,8 \\
Oluyor & 449 & 25,2 \\
Olmuyor & 151 & \\
\hline
\end{tabular}


Yılmaz, Y., \& Kahraman, S. (2019). Şanlıurfa'da adölesan dönemde kızların genital bölge ve hijyeni ile ilgili bilgi, uygulamalar1 ve etkileyen faktörler. Journal of Human Sciences, 16(3), 823-832. doi:10.14687/jhs.v16i3.5678

\begin{tabular}{|l|l|l|}
\hline Vajinal Akıntı Türü & & \\
Grimsi, Balık Kokusu Gibi Kötü Kokulu & 105 & 17,5 \\
Beyaz, Süt Kesiğine Benzer, Peynirimsi & 207 & 34,5 \\
Aşırı Köpüklü, Yeşilimsi, Kötü Kokulu & 8 & 1,3 \\
Sarı ve Bol Miktarda & 56 & 9,3 \\
Şeffaf, Kokusuz & 224 & 37,3 \\
\hline Toplam & 600 & 100,0 \\
\hline
\end{tabular}

Tablo 2'de kızların genital bölge ve hijyeni ile ilgili bilgi durumları verilmiştir. Genital hijyeni kısmen doğru tanımlayan (özel bölge temizliği, koltuk altı ve özel bölge temizliği, tüylerin alınması) kız oranı \%57,2 saptanmıştır. Katılımcıların \% 35,0’1 daha önce "genital bölge ve hijyeni" konusu ile ilgili bilgi almadığını belirtmiştir. Bilgi alan kızlanın \%44,2'si sağlık personelinden bilgi almıştır. Genital bölge temizliğinde doğru malzeme (su ve tuvalet kâğıdının birlikte kullanımı) kullananlar \%28,2 oranındadır. Kızların \%32,5’i tercih ettikleri sabun, şampuan, parfüm, deodorant gibi malzemeleri daha sağlıklı bulmuşlardır. Genital bölgelerini "önden arkaya" doğru temizlediğini ifade eden kızların oranı \%54,9'dur. Kızların \%74,8’i genital bölgesinde kaşıntısı (sık sık veya bazen) olduğunu belirtmiştir. Vajinal akıntının normal bir durum olduğunu düşünen kız oranı \%75,2'dir. Örneklemin \%37,3'ü şeffaf ve kokusuz akıntıya sahiptir.

Tablo 3. Sınıfa Göre Kız Öğrencilerin Genital Bölge Bilgi ve Uygulamaları

\begin{tabular}{|c|c|c|c|c|c|c|c|c|c|}
\hline \multirow{2}{*}{ Değişkenler } & \multicolumn{2}{|c|}{ Lise 1} & \multicolumn{2}{|c|}{ Lise 2} & \multicolumn{2}{|c|}{ Lise 3} & \multicolumn{2}{|c|}{ Lise 4} & \multirow[t]{2}{*}{ Test } \\
\hline & $\mathrm{n}$ & $\%$ & $\mathrm{n}$ & $\%$ & $\mathrm{n}$ & $\%$ & $\mathrm{n}$ & $\%$ & \\
\hline $\begin{array}{l}\text { Bilgi durumu Alma } \\
\text { Almayan } \\
\text { Alan }\end{array}$ & $\begin{array}{l}69 \\
84\end{array}$ & $\begin{array}{l}32,9 \\
21,5\end{array}$ & $\begin{array}{l}56 \\
92\end{array}$ & $\begin{array}{l}26,7 \\
23,6\end{array}$ & $\begin{array}{l}45 \\
142\end{array}$ & $\begin{array}{l}21,4 \\
36,4\end{array}$ & $\begin{array}{l}40 \\
72\end{array}$ & $\begin{array}{l}19,0 \\
18,5\end{array}$ & $\begin{array}{l}\mathrm{X}^{2}=17,237 \\
\mathrm{p}=0,001\end{array}$ \\
\hline $\begin{array}{l}\text { Genital } \\
\text { hijyen tanımı } \\
\text { Bilmiyor } \\
\text { Kısmen doğru }\end{array}$ & $\begin{array}{l}50 \\
103\end{array}$ & $\begin{array}{l}19,5 \\
30,0\end{array}$ & $\begin{array}{l}68 \\
80\end{array}$ & $\begin{array}{l}26,5 \\
23,3\end{array}$ & $\begin{array}{l}81 \\
106\end{array}$ & $\begin{array}{l}31,5 \\
30,9\end{array}$ & $\begin{array}{l}58 \\
54\end{array}$ & $\begin{array}{l}22,6 \\
15,7\end{array}$ & $\begin{array}{l}\mathrm{X}^{2}=10,711 \\
\mathrm{p}=0,013\end{array}$ \\
\hline $\begin{array}{l}\text { Genital bölge tespiti } \\
\text { Bilmiyor } \\
\text { Yanliş } \\
\text { Kismen doğru } \\
\text { Doğru }\end{array}$ & $\begin{array}{l}61 \\
86 \\
4 \\
2\end{array}$ & $\begin{array}{l}20,9 \\
39,3 \\
12,1 \\
3,6\end{array}$ & $\begin{array}{l}62 \\
56 \\
11 \\
19\end{array}$ & $\begin{array}{l}21,2 \\
25,6 \\
33,3 \\
33,9\end{array}$ & $\begin{array}{l}99 \\
53 \\
10 \\
25\end{array}$ & $\begin{array}{l}33,9 \\
24,2 \\
30,3 \\
44,6\end{array}$ & $\begin{array}{l}70 \\
24 \\
8 \\
10\end{array}$ & $\begin{array}{l}4,0 \\
11,0 \\
24,2 \\
17,9\end{array}$ & $\begin{array}{l}\mathrm{X}^{2}=55,339 \\
\mathrm{p}=0,000\end{array}$ \\
\hline $\begin{array}{l}\text { Genital bölge } \\
\text { temizleme yöntemi } \\
\text { Yanlış tercih } \\
\text { Doğru tercih }\end{array}$ & $\begin{array}{l}90 \\
63\end{array}$ & $\begin{array}{l}33,2 \\
19,1\end{array}$ & $\begin{array}{l}59 \\
89\end{array}$ & $\begin{array}{l}21,8 \\
27,1\end{array}$ & $\begin{array}{l}71 \\
116\end{array}$ & $\begin{array}{l}26,2 \\
35,3\end{array}$ & $\begin{array}{l}51 \\
61\end{array}$ & $\begin{array}{l}18,8 \\
18,5\end{array}$ & $\begin{array}{l}\mathrm{X}^{2}=17,121 \\
\mathrm{p}=0,001\end{array}$ \\
\hline $\begin{array}{l}\text { İç çamaşırı tercihi } \\
\text { Bilmiyor } \\
\text { Yanlış tercih } \\
\text { Doğru tercih }\end{array}$ & $\begin{array}{l}67 \\
35 \\
51\end{array}$ & $\begin{array}{l}36,2 \\
26,5 \\
18,0\end{array}$ & $\begin{array}{l}55 \\
33 \\
60\end{array}$ & $\begin{array}{l}29,7 \\
25,0 \\
21,2\end{array}$ & $\begin{array}{l}45 \\
38 \\
104\end{array}$ & $\begin{array}{l}24,3 \\
28,8 \\
36,7\end{array}$ & $\begin{array}{l}18 \\
26 \\
68\end{array}$ & $\begin{array}{l}9,7 \\
19,7 \\
24,0\end{array}$ & $\begin{array}{l}X^{2}=36,096 \\
p=0,000\end{array}$ \\
\hline $\begin{array}{l}\text { Adet olma tanımı } \\
\text { Bilmiyor } \\
\text { Yanlış } \\
\text { Kısmen doğru } \\
\text { Doğru }\end{array}$ & $\begin{array}{l}36 \\
31 \\
82 \\
4\end{array}$ & $\begin{array}{l}24,0 \\
18,7 \\
32,2 \\
13,8\end{array}$ & $\begin{array}{l}27 \\
56 \\
54 \\
11\end{array}$ & $\begin{array}{l}18,0 \\
33,7 \\
21,2 \\
37,9\end{array}$ & $\begin{array}{l}56 \\
50 \\
68 \\
13\end{array}$ & $\begin{array}{l}37,3 \\
30,1 \\
26,7 \\
44,8\end{array}$ & $\begin{array}{l}31 \\
29 \\
51 \\
1\end{array}$ & $\begin{array}{l}20,7 \\
17,5 \\
20,0 \\
3,4\end{array}$ & $\begin{array}{l}\mathrm{X}^{2}=30,291 \\
\mathrm{p}=0,000\end{array}$ \\
\hline
\end{tabular}


Yılmaz, Y., \& Kahraman, S. (2019). Şanlıurfa'da adölesan dönemde kızların genital bölge ve hijyeni ile ilgili bilgi, uygulamalar1 ve etkileyen faktörler. Journal of Human Sciences, 16(3), 823-832. doi:10.14687/jhs.v16i3.5678

$\mathrm{Bu}$ araştırmada Lise 3.'e giden kız öğrencilerin \%30,9' u, Lise 2. Sınıfta okuyan öğrencilerin \%23,3’ü genital hijyen tanımını kısmen doğru yanıtlamıştır $\left(\mathrm{X}^{2}=10,711 \mathrm{p}<0,05\right)$. Lise 1'e giden kızların \%3,6's1 genital bölgeyi (kadın dış ve iç üreme organları) doğru tespitte bulunurken, bu oran Lise 3'e giden kzzlarda yükselmiştir (\%44,6), ( $\mathrm{p}<0,01)$. Genital bölgeyi sağlıklı yöntem (su ve tuvalet kağıdının birlikte kullanımı) ile temizleyen kızların \%19,1'inin lise 1, \%35,3'ünün lise 3 olduğu görülmüştür $\left(\mathrm{X}^{2}=17,121 \mathrm{p}<0,01\right)$. Genital bölgesinde kaşıntı olduğu belirten kıların oran1, Lise 1'de \%27,2, Lise 2'de \%22,5, Lise 3'de \%32,5 ve Lise 4'de \%17,9'dur. Adet olmay1 kısmen doğru (genital bölgeden kan gelmesi, kızlara özgü bir durum, ergenlik dönemine geçiş, doğurganlı̆̆n başlaması) tanımlayan kız öğrencilerin oranı, Lise 1'de \%32,2, Lise 2'de \%21,2, Lise 3'de \%26,7 ve Lise 4'de \%20,0'dır (Tablo 3).

Tablo 4. Merkez İlçelere Göre Kızların Genital Bölge Bilgi ve Uygulamaları

\begin{tabular}{|c|c|c|c|c|c|c|c|}
\hline \multirow{2}{*}{ Değişkenler } & \multicolumn{2}{|c|}{ Eyyübiye } & \multicolumn{2}{|c|}{ Haliliye } & \multicolumn{2}{|c|}{ Karaköprü } & \multirow[t]{2}{*}{ Test } \\
\hline & Say1 & Yüzde & Say1 & Yüzde & Say1 & Yüzde & \\
\hline $\begin{array}{l}\text { Bilgi durumu Alma } \\
\text { Almayan } \\
\text { Alan }\end{array}$ & $\begin{array}{l}67 \\
133 \\
\end{array}$ & $\begin{array}{l}31,9 \\
34,1\end{array}$ & $\begin{array}{l}84 \\
116 \\
\end{array}$ & $\begin{array}{l}40,0 \\
29,7\end{array}$ & $\begin{array}{l}59 \\
141 \\
\end{array}$ & $\begin{array}{l}28,1 \\
36,2\end{array}$ & $\begin{array}{l}X^{2}=7,161 \\
p=0,020\end{array}$ \\
\hline $\begin{array}{l}\text { Genital hijyen tanımı } \\
\text { Bilmiyor } \\
\text { Kısmen doğru }\end{array}$ & $\begin{array}{l}127 \\
73\end{array}$ & $\begin{array}{l}49,4 \\
21,3 \\
\end{array}$ & $\begin{array}{l}41 \\
159 \\
\end{array}$ & $\begin{array}{l}16,0 \\
46,3\end{array}$ & $\begin{array}{l}89 \\
111\end{array}$ & $\begin{array}{l}34,6 \\
32,4\end{array}$ & $\begin{array}{l}\mathrm{X}^{2}=75,852 \\
\mathrm{p}=0,000\end{array}$ \\
\hline $\begin{array}{l}\text { Genital bölge tespiti } \\
\text { Bilmiyor } \\
\text { Yanlış } \\
\text { Kısmen doğru } \\
\text { Doğru }\end{array}$ & $\begin{array}{l}121 \\
40 \\
8 \\
31 \\
\end{array}$ & $\begin{array}{l}41,4 \\
18,3 \\
24,2 \\
55,4\end{array}$ & $\begin{array}{l}55 \\
118 \\
16 \\
11 \\
\end{array}$ & $\begin{array}{l}18,8 \\
53,9 \\
48,5 \\
19,6\end{array}$ & $\begin{array}{l}116 \\
61 \\
9 \\
14\end{array}$ & $\begin{array}{l}39,8 \\
27,8 \\
27,3 \\
25,0\end{array}$ & $\begin{array}{l}\mathrm{X}^{2}=88,29 \\
\mathrm{p}=0,000\end{array}$ \\
\hline $\begin{array}{l}\text { Genital bölge temizleme yöntemi } \\
\text { Yanlış tercih } \\
\text { Doğru tercih }\end{array}$ & $\begin{array}{l}72 \\
128 \\
\end{array}$ & $\begin{array}{l}26,6 \\
38,9\end{array}$ & $\begin{array}{l}115 \\
85\end{array}$ & $\begin{array}{l}42,4 \\
25,8\end{array}$ & $\begin{array}{l}84 \\
116\end{array}$ & $\begin{array}{l}31,0 \\
35,3\end{array}$ & $\begin{array}{l}X^{2}=19,879 \\
p=0,000\end{array}$ \\
\hline $\begin{array}{l}\text { İç çamaşırı tercihi } \\
\text { Bilmiyor } \\
\text { Yanlış tercih } \\
\text { Doğru tercih }\end{array}$ & $\begin{array}{l}65 \\
40 \\
95\end{array}$ & $\begin{array}{l}35,1 \\
30,3 \\
33,6\end{array}$ & $\begin{array}{l}74 \\
51 \\
75\end{array}$ & $\begin{array}{l}40,0 \\
38,7 \\
26,5\end{array}$ & $\begin{array}{l}46 \\
41 \\
113\end{array}$ & $\begin{array}{l}24,9 \\
31,0 \\
39,9\end{array}$ & $\begin{array}{l}X^{2}=15,97 \\
p=0,003\end{array}$ \\
\hline $\begin{array}{l}\text { Adet olma tanımı } \\
\text { Bilmiyor } \\
\text { Yanlış } \\
\text { Kısmen doğru } \\
\text { Doğru }\end{array}$ & $\begin{array}{l}64 \\
44 \\
82 \\
10\end{array}$ & $\begin{array}{l}42,7 \\
26,5 \\
32,2 \\
34,5\end{array}$ & $\begin{array}{l}31 \\
63 \\
98 \\
8\end{array}$ & $\begin{array}{l}20,7 \\
38,0 \\
38,4 \\
27,6\end{array}$ & $\begin{array}{l}55 \\
59 \\
75 \\
11\end{array}$ & $\begin{array}{l}36,6 \\
35,5 \\
29,4 \\
37,9\end{array}$ & $\begin{array}{l}X^{2}=19,02 \\
P=0,004\end{array}$ \\
\hline
\end{tabular}

Eyyübiye ilçesinde yaşayan kızların \%34,1'i daha önce genital bölge ve hijyeni ile ilgili bilgi aldığını ifade ederken, bu oran Haliliye'de \%29,7 ve Karaköprü'de \%36,2 olarak saptanmıstır $\left(\mathrm{X}^{2}=7,16 \mathrm{p}<0,05\right)$. Genital bölge temizliğini doğru yapan kızların \%38,9’u Eyyübiye, \%25,8’i Haliliye, \%35,3’ü Karaköprü ilçelerinde yaşamaktadırlar $\left(X^{2}=19,879 p<0,01\right)$. İç çamaşırını doğru tercih (pamuklu ve beyaz) yapan kı öğrencilerin oran1, Eyyübiye'de \%33,6, Haliliye'de \% 26,5, Karaköprü'de \%39,9'dur $\left(X^{2}=15,97 \mathrm{p}<0,01\right)$. 
Yılmaz, Y., \& Kahraman, S. (2019). Şanlıurfa'da adölesan dönemde kızların genital bölge ve hijyeni ile ilgili bilgi, uygulamalar1 ve etkileyen faktörler. Journal of Human Sciences, 16(3), 823-832. doi:10.14687/jhs.v16i3.5678

\section{Tartışma}

Genital enfeksiyonlardan korunmak için genital hijyenin sağlanması en önemli basamaktır (Ünsal, 2013; Karatay \& Özvarış, 2006). Bu araştırmada yaklaşık üç kız öğrenciden biri daha önce "genital bölge ve hijyeni" konusu ile ilgili bilgi almadığ1 görülmüştür. Bu çalışmaya benzer araştırmaların sonuçlarında da, adölesan kızların üreme sağlığı ile ilgili bilgilerinin olmadığ1 ya da çok eksik olduğu saptanmıştır (Dalbudak, \& Bilgili, 2013; Karatay, \& Özvarış, 2006; Koştu , \& Beydağ, 2009). Bilgi eksikliği nedeniyle bu dönemlerde kızlarda cinsel sağlık ile ilgili sıkıntlar oluşabilir. Ergenliğin ilk dönemlerinden itibaren genital hijyen ile ilgili yeterli bilgi almama, yanlış bilgi ve sonra yanlış uygulama getirebilir. $\mathrm{Bu}$ yanlış uygulama ileride tutum ve davranışlara dönüşebilir. $\mathrm{Bu}$ araştırmanın sonucuna göre bireylere erken adölesan dönemde yanlış bilgi ve uygulamaları engellemek için genital bölge ve hijyeni ile ilgili güncel bilgiler profesyonelce aktarılmalıdır. Yetişkinlerinde eğitim alma olanakları genişletilerek adölesanlar yanlış bilgi ve uygulamalardan uzak tutulabilir.

Kızların perine bölgelerini temizleme şekli ürogenital enfeksiyonların önlenmesi açısından son derece önemlidir. Genital bölgenin su ile yıkanıp, beyaz renkte kaliteli bir tuvalet kağıdı ile önden arkaya doğru bir defada temizlenmesi gerekir. Adölesan kızların genital bölge temizliğinde doğru malzeme tercihi olarak su ve tuvalet kâğıdı kullananlar \%28,2 oranında, genital bölge temizliğini önden arkaya doğru yapanlar \%54,9 oranındadır. Güler ve arkadaşlarının Sivas’ta yaptığ1 çalışmada ilköğretim okulu öğrencilerinin \%69,1’i (Güler, Bekar, Güler, \& et al. 2005). Topuz ve arkadaşlarının Kırıkkale'de yaptığ1 çalışmasında, hemşirelik öğrencilerinin \%86,0’1 (Topuz, et al., 2015), Ünsal'ın Doğu Karadeniz'de yaptığı çalışmasında üniversite öğrencilerinin \%73,9’u genital bölge temizliğini önden arkaya doğru yapmaktadır (Ünsal, Özyazıcıŏglu, \& Sezgin, 2010). Bu çalışmalarda tuvalet kağıdı kullanma oranı \% 8,2-94 arasında değişmektedir (Topuz, et al., 2015; Güler, et al., 2005; Ünsal, et al., 2010). Bu araştırmada doğru yöntemle genital bölge temizleme oranı daha önceki çalışmalara göre daha düşük olup, tuvalet kağıdı kullanma oranı benzerlik göstermektedir.

Vajinal akıntının hacminde artış, kötü koku ya da renginde veya kıvamında değişiklik varsa anormal kabul edilir. Kișilerin vajinal akıntının normal ya da normal dıșı olarak algilamalarında kültürel düzeyi, medyadan, çevreden; özellikle akraba ve yakınlarından duydukları ve gözlemleri gibi sosyal faktörler anahtar rol oynamaktadır (Zincir, \& Temel, 2010; Roberts, Liebenberg, Barnabas, \& Passmore, 2012; Pınar, Çakmak, Saygun., et al., 2009). Bu çalışmada anormal vajinal akıntıya sahip olan kızların oranı \%62,7, genital bölgede kaşıntısı olan kızların oranı \%74,8'dir. Bu kadar yüksek oran olması bu konuda önlemlerin hemen alınması gerekmektedir. Dalbudak ve Bilgili'nin Ankara'da bir hastaneden yaptı̆̆ çalışmada; vajinal enfeksiyona yakalanma riski sentetik iç çamaşırı kullanan kadınlarda 4,5 kat $(\mathrm{p}<0.05)$, renkli iç çamaşıı kullanan kadınlarda 2,2 kat $(\mathrm{p}>0.05)$ artırdığını saptamıştır (Dalbudak, \& Bilgili,2013). Genital ve menstüral hijyene yönelik doğru bilgi ve uygulamaların kazandırılması, sağlı̆̆1 koruma ve sürdürmeye yönelik istendik davranışların geliştirilmesi ve yanlış uygulamaların düzeltilmesi için bu yaş grubunun eğitilmesi çok önemlidir (Topuz, et al., 2015; Zincir, \& Temel, 2010).

Sınıflara göre kızların genital bölge ve hijyeni ile ilgili bilgi ve uygulamalan incelendiğinde; bireylerin sınıfları yükseldikçe bilgi düzeyleri ve doğru hijyen uygulamaları artmaktadır. Bunun nedeni yaşın artması ya da öğretim gördükleri müfredat planı ile ilgili de olabilir. Sınıf değişkenine bakan çalışmalarda sınıf değişkeninin genital hijyen bilgi ve uygulama durumlarında ilişkili olduğunu saptamıştır. Bu çalışmaların sonuçlarına göre genital bölge bilgi durumu ve doğru hijyenik uygulamalar sınıf yükseldikçe artmaktadır (Topuz, et al., 2015; Ünsal, et al., 2010; Karabulutlu, \& Kilıç, 2011; Tartaç, \& Özkan, 2011). Bu nedenle öğretim gördükleri müfredat tekrar gözden geçirilmeli ve konu ile ilgili eğitim adölesan dönem göz önünde tutularak daha erken ve daha sık verilmelidir.

Bu çalş̧mada genital bölge temizliğini doğru yapan kızların \%25,8’i Haliliye, \%35,3’ü Karaköprü İlçesindedir. Bu sonuçlar sosyoekonomik seviyenin bilgiye ulaşma ve uygulamada etkili 
Yılmaz, Y., \& Kahraman, S. (2019). Şanlıurfa'da adölesan dönemde kızların genital bölge ve hijyeni ile ilgili bilgi, uygulamalar1 ve etkileyen faktörler. Journal of Human Sciences, 16(3), 823-832. doi:10.14687/jhs.v16i3.5678

olduğu ve kolaylık sağladığ1 söylenebilir. Turan ve Ceylan'ın İzmir'de yaptığı çalısmada, ilköğretim öğrencileri üzerindeki çalışmasında ise kızların doğru sıklıkta ped değiştirme oranlarının ekonomik düzeylerine göre değiştiğini ve aralarında istatistiksel olarak anlamlı bir fark olduğu ortaya çıkmıştır $(\mathrm{p}<0,05)$ (Turan, \& Ceylan, 2007). Önceden yapılan çalsşmalarda, ailelerin gelir düzeyinin genital hijyeni sağllklı etkileri olduğu doğru bilgi ve uygulamaları olduğunu savunmaktadır (Chandra-Mouli, et al., Fakhri, et al., 2012; 2015; Karatay, \& Özvarış, 2006). Genital bölge uygulamaları ve hijyeni ile ilgili materyallere bu çalışmalara göre yüksek gelir düzeyine sahip ergenler daha kolay ulaşmaktadır. Ayrıca yapılan araştırmalara göre jinekoloji ile ilgili herhangi bir sağlık sorununda yüksek gelir düzeyine sahip olan ergenler sağlık kuruluşlarına daha rahat başvurabilmektedir (Roberts, et al., 2012; Pinar, et al., 2009; Palas, \& Karaçam, 2013).

\section{Sonuç ve Öneriler}

Şanlıurfa il merkezinde genel lise düzeyinde eğitim-öğretim gören adölesan kızların genital hijyen bilgi ve uygulamalarını incelemek amacıyla yapılan bu araştırmada, adölesanların gelir durumu, anne eğitim durumu ve sınıf düzeyinin genital bölge sağlığında etkili değişkenler olduğu saptanmıştır. Kızların genital bölge sağlığı ile ilgili bilgi ve uygulamalarının yetersiz ve eksik olduğu belirlenmiştir.

Öneriler

- Genç kızların sağlıklı olarak büyümeleri için hem okullara yönelik hem de ailelere yönelik bilinçlendirme çalışmalarını yapılması önerilmektedir.

\section{Kaynaklar.}

Aslan, E., Bektaş, H., Başgol, Ş., Demir, S., \& Vural, P.I.(2014). Üniversite Öğrencilerinin Cinsel Sağlık Konusundaki Bilgi Düzeyleri ve Davranışları. TTB Sürekli Tıp Eğitimi Dergisi (STED). 23: 174-82.

Chandra-Mouli, V., Svanemyr, J., Amin, A., et al.(2015). Twenty Years After İnternational Conference on Population and Development: Where Are We With Adolescent Sexual and Reproductive Health and Rights? Journal of Adolescent Health. Suppl 56: 1-6.

Dağ, H., Dönmez, S., Şirin, A., \& Kavlak, O.(2012). Akran Eğitiminin Üniversite Öğrencilerinin Cinsel Sağlık Konusundaki Bilgi Düzeylerine Etkisi. Anadolu Hemşirelik ve Sağlık Bilimleri Dergisi. 15 (1):10-17.

Dalbudak, S., \& Bilgili, N. (2013). GATA Kadın Hastalıkları ve Doğum Polikliniğine Başvuran Kadınların Genital Hijyen Davranışları ve Bu Davranışların Vajinal Enfeksiyona Etkisi. Gülhane Tip Dergisi. 55: 281-87.

Das, P., Baker, K.K., Dutta , A., \& et al. (2015). Menstrual Hygiene Practices, WASH Access and The Risk of Urogenital İnfection in Women From Odisha, India. Plos One. 10: 1-16. Doi: 10.1371/journal.pone. 0130777

Demirbağ, B.C., Çan, G., Köksal, İ., \& Kaya, S.(2013). Üreme Sağlığını Koruma ve Geliştirmede Farklı Yaklaşım: Anne Eğitiminin Kızlarına Aktarılmasının Değerlendirilmesi. Electronic Journal of Vocational Colleges. 12-19.

Fakhri, M., Hamzehgardeshi, Z., Golchin, N.A.H., \& Komili, A. (2012). Promoting Menstrual Health Among Persian Adolescent Girls From Low Socioeconomic Backgrounds: A QuasiExperimental Study. BMC Public Health.12:193.

Güler , G., Bekar, M., Güler, N., \& et al. (2005). İlköğretim Okulu Kız Öğrencilerinde Menstruasyon Dönemi Hijyeni. TTB Sürekli Tip Eğitimi Dergisi (STED). 14 (6): 135-139.

Karabulutlu, Ö., \& Kilıç, M. (2011). Üniversite Öğrencilerinin Cinsel Sağllk ve Üreme Sağllğı Hakkındaki Bilgi Düzeylerinin Belirlenmesi. Anadolu Hemşirelik ve Sağlık Bilimleri Dergisi. 14: 2 . 
Yılmaz, Y., \& Kahraman, S. (2019). Şanlıurfa'da adölesan dönemde kızların genital bölge ve hijyeni ile ilgili bilgi, uygulamalar1 ve etkileyen faktörler. Journal of Human Sciences, 16(3), 823-832. doi:10.14687/jhs.v16i3.5678

Karatay, G, \& Özvarış, Ş.B. (2006).Bir Sağlık Merkezi Bölgesindeki Gecekondularda Yaşayan Kadınların Genital Hijyene İlişkin Uygulamalarının Değerlendirilmesi. Cumhuriyet Üniversitesi Hemşirelik Yüksekokulu Dergisi.10 (1): 7-14.

Koştu, N., \& Beydă̆, K.D.(2009). Jinekoloji Polikliniğine Başvuran Kadınların Genital Hijyen Davranışları. Atatürk Üniversitesi Hemşirelik Yüksekokulu Dergisi. 12 (1): 66-71.

Özcebe, H., \& Dam, A.V.(2007). Gençlik Danışmanlık ve Sağlık Hizmet Merkezleri CSÜS Eğitimi Modülü-Katılımcı Rehberi. T.C. Sağlık Bakanlığı Ana Çocuk Sağllğı ve Aile Planlaması Genel Müdürlüğü. Ankara. 57.

Palas, P., \& Karaçam , Z. (2013). Kadınların Tutuk Evinde Bulunmalarının Genital Hijyen Uygulamalarına Etkisi. Anadolu Hemşirelik ve Sağlık Bilimleri Dergisi. 16 (1): 27-35.

Pınar, T., Çakmak , Z.A., Saygun, M., \& et al. (2009). Gebelikte Anormal Vajinal Akıntı Üzerine Etkili Risk Faktörleri. Tıp Araştırmaları Dergisi. 7 (2): 79-86.

Roberts, L., Liebenberg, L., Barnabas, S., \& Passmore, J. (2012).Vaginal Microbicides To Prevent Human Immune Deficiency Virus Infection in Women: Perspectives on The Female Genital Tract, Sexual Maturity and Mucosal İnflammation. Best Practice Research Clinical Obstetrics and Gynecology. 26: 441-449.

Tartaç, Y., \& Özkan, S.(2011). Lise Öğrencilerinin Menstruasyon Hijyen Konusunda Bilgi/Tutumları ve Eğitimin Etkinliğini Değerlendirme. Gazi Medical Journal. 22: 27-32.

Topuz, S.., Büyükkayacı, N.D., \& Güneş, A.(2015). Sağlık Bilimleri Fakültesi Birinci Sınıftaki Kız Öğrencilerin Genital Hijyen Uygulamaları. Turkish Journal of Clinics and Laboratory. 6(3): 85-90. Doi: $10.18663 /$ tjcl.26388

Turan, T., \& Ceylan, S.S. (2007). 14 Yaş Grubu İlköğretim Öğrencilerinin Menstruasyona Yönelik Bilgileri ve Uygulamaları. Firat Sağlık Hizmetleri Dergisi. 2: 6.

Türkiye İstatistik Kurumu (2017). İstatistiklerle Gençlik. Türkiye İstatistik Kurumu Matbaası. Ankara. .

Ünsal, A. (2013). Hijyen Uygulamaları. Atabek Aştı T, Karadağ A, (Editör). Hemşirelik Esasları Hemşirelik Bilim ve Sanatı. İstanbul, Akademi Yayıncılık, 442-81.

Ünsal, A., Özyazıcıŏlu, N., \& Sezgin, S. (2010). Doğu Karadenizdeki Bir Belde ve Ona Bağlı Dokuz Köyde Yaşayan Bireylerin Genital Hijyen Davranışları. Anadolu Hemşirelik ve Sağllk Bilimleri Dergisi. 13 (2): 12-19.

Zincir, H., \& Temel, A.B. (2010). Riaya Özel Danışmanlık İlkesine Göre Ria Uygulanması, Genital Hijyen Eğitimi ve Vulvo Vajinal Enfeksiyonlarının Görülme İlişkisi. Sağlık Bilimleri Dergisi. 19 (1): 60-67.

\section{Extended English Summary}

Reproductive health is an important part of women's health. According to studies carried out in Turkey, genital infections seem to be a common problem among women in this country. Genital infections are more common and problematic among adolescent girls. In the literature, abnormal vaginal discharge and infections in adolescent girls are second only to dysmenorrhea in reported reproductive health issues. Genital hygiene is essential in order to protect against genital infection When genital hygiene is ignored, susceptibility to genital infection increases. Unless it is treated, it may affect a woman's fertility, and may even cause pelvic inflammatory disease. Genital infections also reduce a woman's quality of life, often leading to social isolation. This, in turn, produces negative effects on a woman's sexual relations and even her family life. Awareness about proper hygiene practices can be provided by the nurse, especially with the education of adolescent women. Because the adolescent period is the most appropriate period in which information about the ways of prevention from genital tract infections, symptoms, diagnosis and treatment methods will be given and new behavioral styles can be gained. This descriptive study aimed to determine the knowledge and practices regarding genital hygiene among adolescent girls in Şanliurfa. 
Yılmaz, Y., \& Kahraman, S. (2019). Şanlıurfa'da adölesan dönemde kızların genital bölge ve hijyeni ile ilgili bilgi, uygulamalar1 ve etkileyen faktörler. Journal of Human Sciences, 16(3), 823-832. doi:10.14687/jhs.v16i3.5678

The population of study was 42358 high school girl students. The sample calculated according the formula from the population was 600 girls. The high school girl students of each central districts of Şanliurfa were determined according to the layered sampling method. The data were collected with questionnaire form and analysed with SPSS 11.5 package program using descriptive statistics an Chi-Square test.

The ratio of girls who answered the definition of genital hygiene as partly true was $57.2 \%$. $35 \%$ of the girls expressed that they did not take any information about genital area and hygiene before. $54.9 \%$ of participants answered cleaning styles of genital area as "front to back". $74.8 \%$ had itching problem in genital area. $75.2 \%$ of the students answered vaginal discharge as a normal condition. $37.3 \%$ had transparent and odorless discharge. The girls who employed healthy cleaning practices (use of both water and toilet paper) attended 1st grade (19.1\%) and 3rdgrade $(35.3 \%)$ in High Schools $(\mathrm{X} 2=17,121 \mathrm{p}<0,01)$.

As a result, the older they get, the more informed they get and the more healthy hygiene practices they have. The study also shows that during early puberty, girls have inadequate knowledge about reproductive health. During this period, they experience genital health problems due to lack of information. As they are not adequately informed about these in early stages of puberty, wrong practices can become ingrained attitudes and behaviours in the future. The earlier research on adolescents comprises 11-14-year-old primary school students, high school or college students. Another factor that increases knowledge is the school year. This is perhaps due to their older age or the curriculum plan. Ardahan, Bay and Demirtaş also examined the school year variable in the research they conducted on nursing students. According to the results, in later school years, their knowledge and accurate hygiene practices increase. However, there has been no research looking into the correlation between the variables of school year and genital hygiene practices.

It is considered abnormal if there is an increase in the volume of vaginal discharge, a bad smell or a change in color or consistency. In the perception of vaginal discharge as normal or abnormal, cultural level of the people is determined by media, environment; social factors such as what they hear and observe from relatives and relatives play a key rol. In this study, the rate of girls with abnormal vaginal discharge was $62.7 \%$ and the rate of itching in the genital area was $74.8 \%$. In such a high rate, precautions should be taken immediately. In a study conducted by Dalbudak and Bilgili from a hospital in Ankara; It was found that the risk of vaginal infection increased 4.5 times $(\mathrm{p}<0.05)$ in women using synthetic underwear and 2.2 times $(\mathrm{p}>0.05)$ in women using colored underwear. It is very important to educate this age group in order to gain the right information and practices for genital and menstrual hygiene, to develop the desired behaviors towards maintaining and maintaining health and to correct the wrong practices.

In the study, the knowledge level and good practices regarding genital area health increased with increased socio-economic level, adolescent age and mother knowledge level and grade. The knowledge level and practices of genital health area were found as inadequate and lacking. It is recommended that awareness-raising activities should be carried out both for schools and families for the healthy growth of young girls. 